I. A WAL NCE LI WRAGICAE WATIONAL LABAAT CAY

\title{
Geolocation Technologies Final Report
}

D. E. Magnoli

June 2, 2003 
This document was prepared as an account of work sponsored by an agency of the United States Government. Neither the United States Government nor the University of California nor any of their employees, makes any warranty, express or implied, or assumes any legal liability or responsibility for the accuracy, completeness, or usefulness of any information, apparatus, product, or process disclosed, or represents that its use would not infringe privately owned rights. Reference herein to any specific commercial product, process, or service by trade name, trademark, manufacturer, or otherwise, does not necessarily constitute or imply its endorsement, recommendation, or favoring by the United States Government or the University of California. The views and opinions of authors expressed herein do not necessarily state or reflect those of the United States Government or the University of California, and shall not be used for advertising or product endorsement purposes.

This work was performed under the auspices of the U.S. Department of Energy by University of California, Lawrence Livermore National Laboratory under Contract W-7405-Eng-48. 


\section{Geolocation Technologies Final Report \\ Douglas E. Magnoli \\ May 15, 2003}

This paper is the final report for LL998 In Situ Sensing Subtask 7 (Geo-location) undertaken for NNSA NA-22 enabling technologies R\&D for Counterproliferation Detection. A few state-of-the-art resolution parameters are presented for accelerometers, indoor and outdoor GPS (Global Positioning Satellite) systems, and INSs (Inertial Navigation Systems). New technologies are described, including one which has demonstrated the ability to track within a building to a resolution of under a foot.

\section{Standard technologies and their capabilites}

Accelerometers have increased significantly in accuracy and decreased in cost with the advent of MEMS construction techniques. Micro-g noise levels are becoming common in commercial off-the-shelf sensors costing a few dollars. These MEMS based devices are also small in size and consume very little power.

Indoor GPS systems are becoming more sensitive. Submeter accuracy in lightly shielded buildings has been demonstrated using massively parallel systems. GPS location accuracy has increased to less than $10 \mathrm{~cm}$ for outdoor line of sight use.

Navigation INS systems have $0.01 \mathrm{deg} / \mathrm{hr}$ drift rates. With additional input from zero velocity updates, or other participating sensors, even systems without beacons should be possible. ${ }^{1}$

\section{$\underline{\text { New technologies }}$}

Other technologies being studied include the cybershoe, a multisensor interface designed for the feet of a dancer. ${ }^{2}$ This system, designed to track a dancer on the stage, makes use of a 3-axis compass, a 3-axis shock accelerometer, a gyroscope, and pressure sensors and is capable of a resolution of 6 inches.

Researchers at the University of Arizona at Tucson are developing a computational system based on the ability of biological systems to sense their own motion by registering the visual flow field as they move. ${ }^{3}$ A prototype system was able to demonstrate that each component of the system was able to correctly recognize the type of motion for

\footnotetext{
${ }^{1}$ See for example, Lawrence J. Hutchings, US Patent No. 6,305,221 B1, Oct. 23, 2001.

${ }^{2}$ Paradiso, J., et al., "The Cybershoe: A Wireless Multisensor Interface for a Dancer's Feet," Proc. Of International Dance and Technology 99, Tempe, AZ, Feb. 26-28, 1999

${ }^{3}$ Higgins, C.M. and Shams, S.A., "A Biologically Inspired Modular VLSI System for Visual Measurement of Self-Motion," IEEE Sensors Journal, vol. 2, no. 6, Dec. 2002
} 
which it was tuned (translation, rotation, etc.) and was not stimulated by motions for which it was not tuned. A combination of such components results in an accurate determination of self-motion.

One contractor (unnamed, because the work is proprietary) is working on an optical deadreckoning module, a system that monitors the visual flow field of a sensor as it moves. The system, still in the experimental stage, picks out fixed points in its environment and judges motion relative to these.

Multispectral Solutions, Inc. (MSSI) has demonstrated a system able to track a human to whom GPS data is unavailable to a resolution of within one foot indoors, and to within a few inches in open terrain. ${ }^{4}$ Their system is based on ultra-wideband radar (UWB).

\section{Details of the MSSI system}

The first demonstration of principle occurred approximately 4-5 years ago, when MSSI was working with Raytheon and DARPA. For that demonstration, the UWB time-delayof-arrival (TDOA) component was merely one of several sensors being used to track units through a 2-mile square area. Other sensors used were magnetometers, accelerometers, gyroscopes, and, when available, GPS. The area over which the units were tracked was largely dense pine forest (impenetrable to GPS) and included several buildings, tunnels, and open spots. When units were in the open spots, GPS was used to update position information. At that time, the UWB TDOA system could not be used by itself to track a unit because there were no UWB reference points, which means that while the UWB system could be used for relative positioning among units, it could not be used for absolute position.

A later incarnation of the system, capable of tracking units without the use of other types of sensors, requires a set of fixed transponders, or beacons, and each unit to be tracked carries a transmitter tag. By comparing TDOA data of each unit's signal to the transponders and back, three-dimensional positioning has been demonstrated to within 1 foot inside buildings and to within a few inches in open terrain, where the signal-to-noise ratio is higher.

The system works by detecting the leading edge of the return pulse. The leading edge of the returning signal is important, because the first signal to return is the one corresponding to the direct-path radar reflection-later signals correspond to multipath returns and reverberation and are not used in computing the positions of the humans. The difficulty of detecting and identifying the leading edge of the signal is that often multipath and reverberation signals are both myriad and of much greater strength than the returning direct-path signal. Furthermore, the leading edge return may also be corrupted by multipath cancellation such that only the leading edge of the pulse remains

\footnotetext{
${ }^{4}$ Fontana, R.J., PhD, Multispectral Solutions, Inc., Gaithersburg, MD, http://www.multispectral.com/pdf/UWBGeolocation.pdf
} 
uncorrupted. MSSI has solved the problem of detecting this low-intensity leading edge by using a quantum tunneling device not described here.

The current system works as follows. The beacons are emplaced (for people entering a building, this can be done at, for example, entries or obvious places in the building, such as corners), and the tag carried by the human emits an RF burst which is received by some of the beacons (or all of them, but it is possible that terrain blockage or excess attenuation prevents some of the beacons from receiving the signal). Each beacon checks to ensure that the message it's receiving is from one of the tags (there is an associated ID message as part of the signal) and after a fixed time (assigned to each beacon to avoid simultaneous reception of pulses from multiple beacons), it sends a reply message containing its own ID.

The tag determines the round trip time-of-flight to each beacon, and from these measurements and knowledge of the location of the beacons, the human's system can determine its position. Since the beacons are capable of at least 100 updates per second, a wealth of data is available.

MSSI is currently manufacturing this system for hospitals, where there is a need to be able to track high-value equipment throughout buildings. (Apparently, hospitals often buy 2-3 times as many of a high-value piece of equipment as they expect to need because no one can ever find one of the things when it's needed - they tend to end up shoved in the back of storage closets, for example. The MSSI system allows hospital employees to know where tracked equipment is at any moment.)

The MSSI system, however, is limited by power considerations to buildings of about 150 feet square. Although MSSI researchers are certain that the system would work in larger buildings at higher power, without applying to the FCC for a license, they are forbidden from testing such higher power systems.

\section{Conclusions}

The state of the art in human geolocation systems is mature enough that private industry should be able to provide systems adequate to meet most operational requirements. Should human geolocation be required in more stressing environments than contemplated here, or in situations in which beacons cannot be emplaced (even temporarily) then a collaboration between private industry and academia should be able to provide a solution. For example, if the Arizona researchers were to incorporate MSSI's UWB radar instead of (or in addition to) a camera as the visual flow-field sensor for their self-motion detector, they would have a system that could (in principle) perform geo-location and mapping without beacons even in zero visibility conditions. 


\section{Distribution:}

Randy Bell (NNSA, DOE, Futterman has address)

$\underline{\text { Mike Carter }}$

Dave Dye

John Futterman

Robert Greenwalt

Rob Hills

Doug Magnoli

Glenn Pomykal

Jenni Pruneda

Tom Ramos

Greg Simonson

David Simons 